\title{
THE TREATMENT OF GASTRIC AND DUODENAL ULCER*
}

\author{
H. LETHEBY TIDY, M.D., F.R.C.P. \\ PHYSICIAN TO ST. THOMAS'S HOSPITAL
}

The evidence bearing on the general results of treatment of gastric and duodenal ulcers is derived from statistics of follow-up departments. I shall confine myself, so far as possible, to those statistics which deal with the resuits of both surgical and medical treatment in the same hospital or in the same groups of patients, not those which are based on the practice of a single physician or surgeon. The results of follow-up investigations are usually divided into several grades according to whether they are satisfactory or unsatisfactory, and although different classifications are used they agree fairly well, on the who'e, with each other. Some, but not many, of the records use the word " cure" for the most successful result.

\section{Criteria of a "Cure",}

We may consider what should be the criteria of a "cure." First the presence of an ulcer must be established. Even so long ago as 1924 Sherren said that clinical diagnoses were correct in. 75 per cent. of the cases on which he operated ; and it is clear that with the advance of radiology diagnosis is becoming more and more accurate. Broster, a few years ago, stated that diagnosis by $x$ rays alone was accurate in $\mathbf{8 0}$ per cent. of cases. The diagnosis of ulcer now is probably correct in 90 per cent. of cases.

The second point in regard to the use of the word cure is that we must know that the ulcer has been healed. Medically, we do not see the ulcer, and we cannot tell if it is healed even when $x$-ray examination shows that a crater previously present has disappeared. After gastro-enterostomy there will be the same doubt as to whether or not the ulcer is cured. Thirdiy, will the treatment undertaken ensure that the ulcer will not recur, or that another ulcer will not develop elsewhere? No layman would agree that we had cured ulcer of the stomach if he was told that he might develop another one a few inches away. We are unable to guarantee immunity from the recurrence of symptoms. A fourth point, and one of importance, is that the treatment must not, in itself, produce any specific bad results, such as, for example, alkalosis or gastro-jejunal ulcers, and it should not have a high mortality. The use of the word cure, in the strict sense, can scarcely be justified, but it is often empioyed in cases in which radiographs have become normal and in which symptoms have been absent for a long time.

\section{Results Indicąted by "Follow-up"}

The first results to be considered are those of the followup department of St. Bartholomew's Hospital, which were published last year. This department was new in 1929, and the results are those of careful observation for one to five years. Table I gives the figures for chronic ulcers. Since many of the cases will have been followed only for short periods, the figures will not show relapses, failures, or other sequelae in full. Grades I and II may be

* The Harveian Lecture, delivered to the Harveian Society of London on March 12th, 1936. regarded as "satisfactory" from the patient's point of view and Grade III as " unsatisfactory." Cases in Grade IV must be regarded as complete failures, and to these must be added the cases with a fatal termination.

TABLE I.-Results of Treatment of Chronic Duodenal and Gastric Ulcer St. Bartholomew's Hospital, 1929-34

\begin{tabular}{|c|c|c|c|c|c|c|c|c|}
\hline & \multicolumn{4}{|c|}{ Duodenal Ulcer } & \multicolumn{4}{|c|}{ Gastric Ulcer } \\
\hline & \multicolumn{2}{|c|}{ Medical } & \multicolumn{2}{|c|}{ Surgical } & \multicolumn{2}{|c|}{ Medical } & \multicolumn{2}{|c|}{ Surgical } \\
\hline & No. & $\begin{array}{c}\text { Per } \\
\text { cent. }\end{array}$ & No. & $\begin{array}{l}\text { Per } \\
\text { cent. }\end{array}$ & No. & $\begin{array}{c}\text { Per } \\
\text { cent. }\end{array}$ & No. & $\begin{array}{l}\text { Per } \\
\text { cent }\end{array}$ \\
\hline Grade I: No symptoms & 48 & 35.3 & 64 & 52 & 83 & 36 & 52 & 43.3 \\
\hline Grade II : Few symptoms & 22 & 16.6 & 20 & 15.2 & 44 & 19.1 & 17 & 14.2 \\
\hline Grade III: Pain and inca- & 18 & 13.6 & 12 & 9.8 & 19 & 8.2 & 5 & 4.2 \\
\hline $\begin{array}{l}\text { Grade IV : Definite active } \\
\text { ulcer }\end{array}$ & 33 & 25.2 & 13 & 10.6 & 51 & 22.1 & 13 & 10.8 \\
\hline $\begin{array}{l}\text { Deaths: Immediate } \quad \ldots \\
\text { Ders }\end{array}$ & 7 & 5.3 & 6 & 4.9 & 15 & 6.5 & 25 & $2 c .8$ \\
\hline Ie ths: Late $\quad \ldots \quad \ldots$ & 4 & 3.0 & 8 & 6.5 & 10 & 4.3 & 8 & 6.7 \\
\hline Gastro-jejunal ulcers ... & 131 & & 123 . & 6.8 & 222 & & 120 & \\
\hline $\begin{array}{lllll}\text { Lost } & \ldots & \ldots & \ldots & \ldots\end{array}$ & & & & & 8 & & & \\
\hline
\end{tabular}

With regard to duodenal ulcer, surgery gives a higher proportion of Grade I cases than does medical treatment, and this will be the general experience. The disproportion is less when Grades I and II are taken together. The deaths under medical treatment contain a fallacy which applies also to the figures for gastric ulcer and is common in most statistics. The majority of these deaths are due to severe haemorrhage in patients who are gravely ill on admission, who die before receiving any appreciable medical treatment, and on many of whom a surgeon would be unwilling to operate. These deaths occur in medical wards, but not while the patients are under medical treatment; they should therefore be classified separately as are cases of perforated ulcer in surgical wards. Thus the percentage mortality under medical treatment is much less than the 8.3 shown in this table. The ulcer perforated in six cases which were under medical treatment (4.5 per cent.), a serious feature, though presumably all the patients did not die. Under surgical treatment the immediate operative mortality is 4.9 per cent. with an additional late mortality of 6.5 per cent.-a total of 11.4 per cent. The frequency of gastro-jejunal ulcers is here 6.8 per cent., but the follow-up is not long enough to show the full effect of this sequela of treatment.

Concerning the figures for gastric ulcer, the medical cases had all failed under out-patient treatment, and the surgical had received no medical treatment in the wards. The results under medical treatment are similar to those for duodenal ulcer. Perforation occurred in eleven cases (5 per cent.), and in seven of these the patient died (3.2 per cent.). Surgical treatment gives approximately the

[3935] 
same results as medical treatment for Grades I and II. The immediate mortality of operation is here 20.8 per cent., and the total operative mortality 27.5 per cent. Perforated ulcers are not included. It is impossible to study these figures without grave concern.* In view of the results which have been attributed to surgical treatment they may be read with considerable surprise.

Table II gives statistics from the Peter Bent Brigham Hospital, Boston; it is customary in America to classify

TABLE II.-Results of Treatment of Peptic Ulcers Peter Bent Brigham Ho ppital, Boston, 1913-32

\begin{tabular}{lll|c|c|c|c}
\hline & & \multicolumn{2}{|c|}{ Medical } & \multicolumn{2}{c}{ Surgical } \\
\cline { 5 - 7 } & & No. & Per cent. & No. & Per cent. \\
\hline No symptoms ... & $\ldots$ & $\ldots$ & 149 & 13.7 & 91 & 19.0 \\
Verr few symptoms & $\ldots$ & 397 & 36.5 & 93 & 19.3 \\
Definite improvement & $\ldots$ & 335 & 30.8 & 119 & 24.8 \\
Improvement & $\ldots$ & $\ldots$ & 69 & 6.3 & 39 & 81 \\
No improvement & $\ldots$ & $\ldots$ & 135 & 12.5 & 138 & 28.7 \\
\hline & & & 1,085 & & 480 & \\
\hline
\end{tabular}

duodenal and gastric ulcers together as peptic ulcers. The "follow-up" was conducted over long periods, the shortest being two years. The classification may be considered as closely similar to that adopted by St. Bartholomew's Hospital. Surgical treatment gives a somewhat higher percentage than medical in the first grade, but the " satisfactory" results are 50 per cent. under medical and 38 per cent. under surgical treatment. The failures are 12 per cent. under medical and 28 per cent. under surgical treatment. The proportion of gastro-jejunal ulcers is 9.7 per cent., and as this is calculated on all forms of peptic ulcers under all surgical methods it must be due to a much higher frequency in those operative procedures with which this sequela is usually associated.

It is a matter of great importance to those who are undergoing treatment for ulcers to know what their expectation of working life will be afterwards, and under which treatment, medical or surgical, they will be the best wage-earners, and which will give them the least invalidism. They will want to know whether they will be free from symptoms, or, again, if medical treatment has

TABLE III.-Working Capacity after Peptic Ulcers Post Office : 3-20 years. Absences per Year for Digestive Disorders

\begin{tabular}{|c|c|c|c|c|c|}
\hline & & \multicolumn{2}{|c|}{$\begin{array}{l}\text { Average Annual } \\
\text { Absence in Days }\end{array}$} & \multicolumn{2}{|c|}{$\begin{array}{c}\text { Average Annual } \\
\text { Absence Exceeding } \\
1 \text { Month }\end{array}$} \\
\hline & & Medical & Surgical & Medical & Surgical \\
\hline Duodenal ulcer & $\begin{array}{c}\text { Manual workers } \\
\text { Non-manual }\end{array}$ & $\begin{array}{l}12.5 \\
10.5\end{array}$ & $\left.\begin{array}{r}15.6 \\
9.4\end{array}\right\}$ & $\begin{array}{c}\text { Per cent. } \\
10\end{array}$ & $\underset{12}{\text { Percent. }}$ \\
\hline Gastric ulcer & $\begin{array}{l}\text { Manual workers } \\
\text { Non-manual }\end{array}$ & $\begin{array}{l}16.4 \\
12.1\end{array}$ & $\left.\begin{array}{l}15.5 \\
10.7\end{array}\right\}$ & 15 & 14 \\
\hline
\end{tabular}

been tried and failed, whether they will be wise to turn to surgery in the fair expectation of a successful result. Bashford and Scott calculated the invalidism over a prolonged period for digestive disorders following treatment for peptic ulcers among employees of the Post Office. A summary of the results is given in Table III. These deal with working capacity, and immediate mortality under treatment is not exhibited. The " average annual

* The figures for St. Thomas's Hospital for the same period give an immediate operative mortality of 15 per cent. absence exceeding one month" is some measure of the amount of serious illness, and is a depressing feature. As in other statistics gastric ulcer appears as more serious than duodenal ulcer. There is little difference between medical and surgical treatment, and it would appear that for those who survive the considerable operative mortality of surgical treatment the expectation of working capacity is no better than it is after medical treatment.

The medical profession is in a special position to obtain expert treatment and to use its own experience in deciding what line to adopt. Forsyth in 1924 classified the claims on the Medical Sickness, Annuity and Life Assurance Society for duodenal ulcer. These claims are confined to the medical profession, and are for total working incapacity only. The results are summarized in Table IV.

TABLE IV.-Duodenal Ulcer among Medical Men Medical Sickness, Annuity, and Life Assurance Society Total cases $=59$. Relapses $=37$ per cent. (Total incapacity)

\begin{tabular}{lccc|c|c}
\hline & & & $\begin{array}{c}\text { Medical } \\
\text { Treatment }\end{array}$ & $\begin{array}{c}\text { Surgical } \\
\text { Treatment }\end{array}$ \\
\hline Number of cases & $\ldots$ & $\ldots$ & $\ldots$ & 26 & 33 \\
Total sickness claims ... & $\ldots$ & $\ldots$ & 53 (2 per case) & 66 (2 per case) \\
Average period of invalidity & $\ldots$ & $4 \frac{1}{2}$ months & 5 months \\
Invalidity exceeding 5 months & $\ldots$ & $3=12$ per cent. & $11=33$ per cent. \\
No recurrence in 1-12 years & $\ldots$ & $16=62$ per cent. & $19=58$ per cent. \\
Recurrence in $1-10$ years & $\ldots$ & $\ldots$ & $10=38$ per cent. & $12=36$ per cent. \\
Deaths ... $\quad .$. & $\ldots$ & $\ldots$ & $\ldots$ & 0 & 3 (operation) \\
Re-operation in $1-16$ years & $\ldots$ & $\ldots$ & & 4 \\
\hline
\end{tabular}

Two special points of difference appear. First, under surgical treatment there are three deaths in thirty-three cases, and under medical treatment there are no deaths. Secondly, claims for invalidity exceeding five months numbered eleven, or 33 per cent., of the surgical cases, and three, or 12 per cent., of the medical cases.

In general these figures agree with the statistics already quoted. Those who survive the considerable operative mortality subsequently run a greater risk of prolonged invalidism-partly due to gastro-jejunal ulcer-than do those who undergo medical treatment, but otherwise there is little difference in the frequency of relapses. Forsyth noted that in twenty-three cases which were operated upon at the time of the first claim relapses involving total incapacity occurred in 39 per cent., the same proportion as for the total series. This does not afford evidence that surgical failures can be ascribed to delay in resorting to radical measures.

Two other series of statistics may be briefly mentioned. Dr. David Smith has published the follow-up results in cases of peptic ulcer treated medically at the Royal Infirmary, Glasgow (Table V). The records are of

$$
\text { TABLE V.-Results of Medical Treatment }
$$
Royal Infirmary, Glasgow.

\begin{tabular}{|c|c|c|c|c|c|c|c|}
\hline & & & & \multicolumn{2}{|c|}{ Immediate Results } & \multicolumn{2}{|c|}{ 5-15 Years } \\
\hline & No. & Per cent. & No. & Per cent. \\
\hline Cured ... & ... & $\ldots$ & $\ldots$ & 153 & 74.6 & 75. & 39.2 \\
\hline Improved & ... & $\ldots$ & $\ldots$ & 38 & 18.5 & 38 & 20.0 \\
\hline Failures... & $\ldots$ & $\ldots$ & $\ldots$ & 6 & 2.9 & 59 & 31.2 \\
\hline \multirow{3}{*}{\multicolumn{4}{|c|}{ 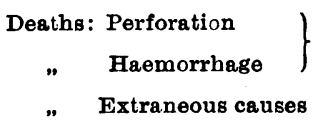 }} & 8 & 4 & 6 & 3.2 \\
\hline & & & & 8 & 4.0 & 12 & 6.4 \\
\hline & & & & & & 12 & \\
\hline \multicolumn{3}{|c|}{ Irregular dismissals } & ... & 3 & & & \\
\hline Lost & . & ... & $\therefore$ & & & 6 & \\
\hline Deaths: $\mathbf{P}$ & to & tive & ... & & & 6 & \\
\hline
\end{tabular}


interest as showing the immediate and late results on the same series of patients and the mortality which may be expected. (Post-operative deaths and all cases operated upon are included in "failures.") David Smith found that the operative mortality in cases resistant to medical treatment was 19 per cent.

The British Medical Association in 1929 and 1930 published the statistics of a collective investigation of the results of gastro-enterostomy. The investigation was confined to one operative method and necessarily was not on "follow-up" lines. The immediate mortality in duodenal and pyloric ulcers was given as 4.3 per cent. and in gastric ulcers as 8.9 per cent. The full statistics are of surgical interest, but were not framed to apply to the treatment of ulcers in general or to the after-results.

\section{Review of Results}

The statistics here brought forward from reliable sources show a more serious condition of affairs than would generally be expected. We see what an unfavourable outlook there is for the patient who has either a gastric or a duodenal ulcer. In duodenal ulcer surgery can offer a higher proportion of definite, and what may be called permanent, cures than can medicine, but the percentage is not high. The immediate operative mortality is about 5 per cent., with an additional late mortality which is not less. The risk of the serious sequela of gastro-jejunal ulcer is uncertain, but on the results of the short followup of St. Bartholomew's Hospital, and the longer results of the Peter Bent Brigham Hospital, which includes other conditions it can scarcely be less than 10 per cent. and may be appreciably more. Compared with these serious surgical risks there is under medical treatment a risk of fatal perforation which does not exceed 4 per cent. over prolonged periods. The expectation of working capacity is somewhat greater on medical than on surgical treatment. Thus surgical treatment can offer more chance of a "satisfactory" result and a relative immunity from perforation, but unless these statistics possess some extensive flaw it is a serious responsibility to advise operation for duodenal ulcer in view of the operative mortality and the risk of gastro-jejunal ulceration.

Gastric ulcer is a more serious condition than duodenal ulcer. There is no appreciable difference between medical and surgical treatment in the chance of a " satisfactory" result or the expectation of working capacity subsequent to the period of treatment, but the operative mortality under favourab'e conditions may approach 20 per cent. Unless, again, these statistics possess some serious flaw, it is a grave responsibility to advise a patient with gastric ulcer to undergo an operation which involves a very high mortality and has no subsequent advantage over medical treatment.

\section{Can these Results be Improved?}

First there is the factor expressed in the frequent complaint that we " should get our cases earier," and there is no doubt that the earlier a case receives systematic treatment, medical or surgical, the better are the results. Many patients with vague digestive symptoms are "cured," satisfactorily for the moment but with the loss of after-treatment, by a couple of bottles of alkaline medicine. Radiology has taught us that vague digestive disturbances may be due to ulceration. Nicholas and Moncrieff showed that where there had been a radiologically demonstrable u.cer crater which disappeared under treatment a return of symptoms was accompanied by a return of the crater. The diagnosis will probably continue to be made earlier and earlier as knowledge advances, and end-results will thus improve.

Secondly, there is the difficulty of after-treatment. It is clear that we have not solved the after-treatment any more than we have the immediate treatment. A patient may follow all directions conscientiously but the ulcer may not heal, relapses and haemorrhages may develop, and gastro-jejunal ulcers may form. It may be noted that the statistics which have been quoted are from follow-up departments in which the patients are under some measure of observation and encouragement. But there is no doubt of the importance of after-treatment under either medical or surgical methods. The " satisfactory result" presents special danger, as Lord Horder has emphasized. When the patient has felt well for several years and is convinced that he is safe he relaxes his precautions and is shocked by the ensuing catastrophe.

Thirdly, there is the question whether the medical and surgical " satisfactory results " are derived from the same class of case ; this applies also to medical and surgical "failures." Does a certain class give " satisfactory results" under either method and another class "failures"? If the grouping is different then it might become possible to recognize whether an individual patient should be treated medically or surgically. Hitherto it has been widely assumed that if medical treatment has failed surgical treatment is indicated.

In certain circumstances difficulties are encountered with medical treatment:

1. Social Status and Occupation.-The manual worker and labourer is handicapped with regard to after-treatment, especially as to diet. The directions for after-treatment, whether following operation or medical treatment, differ little as to diet, and if a patient's diet is unsuitable for one method it is also unsuitable for the other. The Post Office records afford no evidence that manual workers do better after surgical than after medical treatment, though individual cases may require special consideration.

2. Obstructive Lesions.- Such conditions in general obviously require surgery.

3. Hyperacidity.-Prognosis is not greatly influenced by hyperchlorhydria, but it is unfavourable when this is combined with hypersecretion-that is to say, when there is a large volume of fasting juice with a high acidity. When this occurs in duodenal ulcer, gastro-enterostomy involves a high risk of gastro-jejunal ulcer.

4. Haemorrhage.-The treatment of severe haemorrhage is referred to later. Recurrent haemorrhages are naturally a cause of great anxiety to the patient, but the risk of death after the initial attack is small. In the Peter Bent Brigham Hospital there were only twenty deaths in two to twenty years among some 1,500 cases of ulcer. In Forsyth's series there were no deaths, although he mentions that there were several instances of repeated haemorrhages. Recurrent haemorrhages may sometimes cease after operation as they may at any stage after medical treatment, but operation cannot be relied upon to bring this about. The results from the Peter Bent Brigham Hospital are identical whether following medical or surgical treatment (Table VI). It does not appear that

TABLE VI.-Haemorrhage in Relation to Treatment Peter Bent Brigham Hospital. 2-20 years.

\begin{tabular}{|c|c|c|c|c|c|c|}
\hline \multirow{2}{*}{\multicolumn{3}{|c|}{ Treatment }} & \multirow{2}{*}{$\begin{array}{l}\text { Number } \\
\text { of cases }\end{array}$} & \multicolumn{2}{|c|}{$\begin{array}{l}\text { After-treatment } \\
\text { Haemorrhage }\end{array}$} & \multirow{2}{*}{$\begin{array}{c}\text { Haemorrhage } \\
\text { Only } \\
\text { After 'Treat- } \\
\text { ment } \\
\text { (Number) }\end{array}$} \\
\hline & & & & Ceased & Recurred & \\
\hline Medical & ... & $\ldots$ & 170 & $\begin{array}{c}\text { Per cent. } \\
76\end{array}$ & $\begin{array}{c}\text { Per cent. } \\
24\end{array}$ & 32 \\
\hline Suricical & $\ldots$ & $\ldots$ & 123 & 78 & 22 & 32 \\
\hline
\end{tabular}

repeated haemorrhage is a reason for recommending operation.

5. Large Adherent Gastric Ulcers.-These can often be diagnosed on the radiological appearance and on the 
symptoms. The pain is usually severe, is felt in the back, and is often troublesome at night. It is well known that these ulcers are resistant to medical treatment, and after prolonged treatment operation may reveal a large unhealed adherent ulcer. This is evidence of the failure of medical treatment, but since the latter has been shown to be not inferior to surgery in the treatment of gastric ulcer, the presence of an unhealed adherent ulcer is not $i p s o$ facto an indication for routine operation. Given that the diagnosis has been made before operation, the patient may wish to know if his future will be improved by submitting to the radical procedure. In many cases the operation will resolve itself into a gastro-enterostomy, which will leave the ulcer untouched. Bearing in mind the operative mortality associated with gastric ulcer, the view widely held that such ulcers are a definite indication for surgery needs reconsideration and some evidence in support of it. It may be best for the patient to accept a:l unsatisfactory result rather than an equally unsatisfactory one together with the risks consequent on a considerable operative mortality.

6. Relapses Under Medical Treatment.-Relapses or failures may occur after or during the most careful routine. It has been generally assumed that such an occurrence is an indication for operation. This assumption is based on the belief that surgical results are better than medical, and, further, that medical failures will, with reasonable probability, become surgical successes. The usual indication for operation is the persistence of abdominal pain which is not relieved by strict medical treatment. There is no doubt that such pain is completely relieved in many cases for a period immediately following operation, especially gastro-enterostomy for duodenal ulcer. The immediate operative mortality is not negligible in duodenal ulcer and is a grave factor in gastric ulcer.

The later results according to the statistics already quoted suggest that these favourable results in those who survive the operation are not permanent. Thus the patient with duodenal ulcer has to face the fact that gastro-jejunal ulcer develops in not less than 10 per cent. of cases operated on, and also that if symptoms return after operation further treatment is usually ineffectual. No doubt some cases will do better permanently after surgical measures than after medical, but there is little indication as to which they are. An ulcer which is resistant to medical treatment cannot be assumed to be amenable to operation for more than an uncertain period or to indicate its performance as a routine. David Smith found that ulcers which were resistant to one course of medical treatment might yield to a second, a finding within general experience. It is also a general experience that a surgical faiiure is unlikely to yield to any further form of treatment.

The probable position is that, in general, medical successes and failures occur in the same cases as do surgical successes and failures. Such phrases as "medical treatment shou'd be given a fair but not too lengthy a trial" and "medical treatment has been tried and failed so an operation is indicated " need to be carefully reconsidered in the light of the operative mortality and the late results.

\section{Severe Haematemesis and Melaena}

It cannot be far wrong to say that haemorrhage to a degree appearing as a symptom occurs in 25 to 33 per cent. of cases diagnosed as peptic ulcer. In these cases the mortality from haemorrhage is probably from 2 to 4 per cent., much of the bleeding being of little importance from the point of view of loss of blood or danger to life. I shall here confine myself to the consideration of severe haemorrhage, the standard for which may be accepted as that degree which would cause the patient to be admitted to hospital directly and immediately for gross haematemesis or gross melaena. In this group the mortality is from 10 to 20 per cent., the figure depending on the standard of haemorrhage accepted by the recorder. It is important to consider whether a smaller class can be separated from this group to which the mortality is mainly due.

First, the dreaded feature of a " second haemorrhage" may be mentioned. There are two different circumstances in which a second haemorrhage may occur: either at an appreciable interval after the first or close on its heels. As to the former, a patient may have second, third, or further haemorrhages at intervals of two or more years, the blood having time to recover between the recurrences. The tendency to such haemorrhage is apparently not checked by operation as mentioned above. The risk from such a recurrence is approximately the same as from a first haemorrhage, and there is no reason on numerical grounds why it should be treated differently.

Probably the greatest danger to life is from a first haemorrhage. But when severe haemorrhage takes place it is of little matter whether it is from an acute or chronic ulcer, or whether it is a first or second attack; the seriousness depends on the amount of bleeding at the moment. It is a mistake to say " this is an acute ulcer, so the haemorrhage should be treated medically." If the haemorrhage is severe the possibility that an artery has been opened just as surely as if it had been cut across must be considered in all cases, though recognizing that the bleeding point may be more difficult to identify in some circumstances than in others.

Progressive studies by Bulmer, Aitken, Lloyd Davies and Nevin, and others have separated a group with a high, mortality which accounts for nearly all the deaths. These studies were of patients with severe haemorrhage or melaena for which they were admitted, or which developed during their stay in hospital. In this group a second haemorrhage within twenty-four hours involves a mortality of $\mathbf{7 0}$ to $\mathbf{8 0}$ per cent., and is thus of grave significance.

Lloyd Davies and Nevin divide the group into two classes:

1. Severe.-Haemoglobin under 20 per cent., and clinical condition grave. The mortality is 46 per cent. in the absence of surgical treatment.

2. Moderate.-Haemoglobin over 20 per cent., clinical condition not grave. The mortality is 6 per cent. in the absence of surgical treatment.

The term " moderate" is only comparative, as in all cases there was gross haemorrhage. About 40 per cent. of the cases fall into the " severe" class and 60 per cent. into the " moderate" class. As Aitken says, it is not difficult to distinguish the two classes clinically.

The comparative safety of the " moderate" class may be due partly to the possibility of surviving a certain further amount of bleeding if the haemoglobin is 30 per cent., but not if it is 20 per cent.

There can be no doubt that the danger to life is from the bleeding which is taking place at the moment, not from the after-results. Subsequently these cases do as well as any others, and many authorities believe that they do better. Hence it is surely missing the point to say, " Do not operate during the haemorrhage but as soon as possible afterwards," or, as we have all done, "Give a blood transfusion and watch and reconsider in two days." An ordinary blood transfusion will benefit the patient, but the results at St. Thomas's Hospital do not suggest that it will materially reduce the mortality in the severe class.

Lloyd Davies and Nevin found from the post-mortem reports that in 70 to 80 per cent. of fatal cases there was a definite bleeding vessel capable of ligation. Of course 
this is not evidence that the bleeding vessel could have been identified at operation. Unfortunately there are no satisfactory statistics of the resu'ts of operation in a series of these severe cases; but the mortality in the absence of operation is so high, and, as post-mortem records show, is so inevitable that it may be suggested that the correct procedure in the severe group is to run all risks and operate immediately in the hope of being able to ligature or close the b'eeding vessel.

The sole object and reason for operating in haemorrhage should be to find and deal with the bleeding point or bleeding site, and if this cannot be accomplished the patient shou'd not be exposed to further risks by other operative procedures. The continuous drip blood transfusion, for the introduction of which the Middlesex Hospital surgeons deserve very high praise, will restore otherwise almost hopeless cases to a condition from which there is a reasonable chance of recovery.

\section{Moderate Haemorrhage}

I am here referring to cases in which frank haemorrhage has occurred, but in which the haemog'obin is not below 20 per cent. and the clinical condition is not grave at the moment. The mortality is about 6 per cent., which is not greater than the operative mortality, although even among these cases some of the deaths are due to a second haemorrhage, a factor that would bring them into the class in which operation is indicated.

Let us assume that a patient has 30 per cent. of haemog.obin. It is essential that the haemoglobin should be watched frequently; if it falls an operation should be performed, otherwise treatment should be medical. The latter is often assumed to be injections of morphine and nothing by the mouth until haemorrhage has ceased. The injection of morphine may be accepted, as the patient is usually anxious and restless, but the prolonged withholding of food is irrational and there is no evidence of its value. A stomach is not kept at rest by prolonged starvation; this is most efficiently achieved by easily digested food, milk, and eggs, in small amounts at short intervals. We should consider it folly to keep a patient with 30 per cent. of haemoglobin without nourishment for forty-eight hours in any other circumstances, but we hear of patients after a haemorrhage being kept for three days or more without food. Nourishment may be withheld for twelve hours, or even possibly twentyfour, but not longer. In the next twenty-four hours about one pint of milk with two beaten-up eggs should be given two-hourly in amounts of two ounces, and this quantity should be gradually increased daily. Alkalis should also be given, avoiding those which set free gas.

Meulengracht has recently advocated a surprisingly varied diet from the onset. I agree with him in the revu'sion from the starvation system for haemorrhage, but I doubt the wisdom of going so far in the first few days. His system clearly cannot apply to the " severe" haemorrhage group, in which the danger comes from an open artery.

\section{Medical Treatment of Peptic Ulcers}

Our routine treatment is hampered by ignorance of the true pathogenesis of peptic ulceration. Hyperacidity, with hypersecretion, is often associated with ulceration and affects the prognosis and the results of treatment, but many ulcers develop in the absence of hyperacidity. Sepsis cannot be considered to be more than a subsidiary factor. The influence of pre-existing gastritis is unproved. An essential factor may exist of which we are ignorant.

Two general principles in the treatment of an active ulcer are usually accepted: (1) to procure rest for the stomach, and (2) to prevent a strong gastric juice bathing the ulcer. Rest involves the diminution of muscu'ar contractions. Starvation does not prevent peristalsis, nor does it prevent the secretion of juice or protect the ulcer. The frequent administration of small, easily digested meals may rest the stomach and protect the ulcer for about an hour. The best general rule is " to do something every hour " and may be met by giving food every two hours and alkalis in the intervening hours, but such administration of alkalis in sufficient doses cannot be prolonged. Sippy's method of giving food every hour is the most logical and probably gives the best results, but it has difficulties in practice, though these are not so great as might be thought. Milk and eggs have, perforce, to form the basis of the diet. They are nourishing, they do not cause much peristalsis, and they help to neutralize gastric juice. Provided that the principles are followed the details of the diet are open to considerable variation without any appreciable difference in the results. It is essential that the night should not pass without treatment.

Hurst is opposed to the graduations of diet, which are often elaborately compcsed. He argues that, logically, the correct diet should be decided at the onset and adhered to until convalescence. I agree with the basis of this system, as I believe that, in general, patients suffering from ulcers are underfed as to quantity in the early stages for no obvious reason. Personally I use a modification of Lenhartz's original diet, but without making any special claims for it. The principles are of more importance than the minor details.

In after-treatment it is essential that the stomach should never be long without some food, not longer than two and a half hours, and this should be maintained throughout life. Sufferers from ulcers and the medical profession are agreed that alkalis are indicated. I like patients to take alkalis almost continuously for six months, and then gradually omit them for periods, but always to take a course for two months twice a year. A feed of milk and a dose of alkali should always be ready by the bedside at night. No after-treatment, however strictly adhered to, can be guaranteed to prevent relapses, but there is no doubt that those who are careful are more likely to escape than the careless.

Histidine Treatment.-This is based on an entirely different principle from the others. If the results are substantiated by experience it would appear that histidine protects the mucous membrane or prevents the action of some destructive factor other than $\mathrm{HCl}$. The results which I have had so far have been encouraging. I have had one apparent failure to relieve pain in a nervous subject. In the other five cases in which it has been used the immediate results have been successful. One case may be quoted.

The patient was a man aged 40 , with a history of severe pain for four and a half years. He had not touched meat for two years, but received no relief from his abstinence. $\mathrm{He}$ was given injections of histidine, a full diet, and no alkalis; he was allowed up and helped in the work of the ward. For two or three days he was unwilling to take the normal midday meat meal of the ward, but afterwards he took it freely without ill effects, being encouraged to do so by another patient somewhat ahead of him in the course. He lost all pain in six days and muscular rigidity in about ten or twelve days. The radiographs showed a large ulcer crater before treatment which is not visible in that taken three weeks later.

Similar disappearance of an ulcer crater occurs with other forms of treatment, as Davies, among others, has recently shown, and is not proof that the ulcer is healed. But such disappearance combined with absence of symptoms may be regarded temporarily as an indication of successful treatment. Nevertheless, it would be wise to suspend judgement. 


\section{Conclusions}

1. Medical and surgical treatment of peptic ulcers give approximateiy the same late results, judged by the frequency of failures and relapses and subsequent working capacity.

2. The operative mortality is considerable and is higher than has been generally believed, especially in the case of gastric ulcers, in which it may be between 10 and 20 per cent. under favourable circumstances.

3. The immediate results of gastro-enterostomy for duodenal uicer are appreciably better than those of medical treatment.

4. The incidence of gastro-jejunal ulcer after gastroenterostomy for duodenal ulcer is not less than 10 per cent.

5. Evidence is lacking to support the view that cases which are medical failures will in general do better permanently after operation, or will do sufficiently better to counterbalance the operative mortality and the risk of gastro-jejunal ulcer.

6. Cases which relapse after a first course of medical treatment may be successfully treated by a second.
7. Grave cases of haemorrhage from peptic ulcer have so high a mortality that operation is indicated to check the bleeding point. There is no indication for operating when haemorrhage has ceased.

8. The medical treatment of haemorrhage should not involve prolonged starvation.

9. The medical treatment of active peptic ulcer should be based on the principle that the stomach is not left for more than two hours without treatment.

BiBLIOGRAPHY

Aitken, R. S.: Lancet, 1934, i, 839

Bashford, H. H., and Scott, W. L.: Ibid., 1935, ii, 710.

Broster, L. R.: British Medical Journal, 1928, ii, 786.

Bulmer, E.: Lancet, 1932, ii, 720.

Davies, T. A. Lloyd, and Nevin, R. W.: Ibid., 1934, ii, 858.

Emery, E. S., -and Monroe, R. T. (Peter Bent Brigham Hospital) : Arch. Int. Med., 1935, lv, 27.

Forsyth, D.: British Medical Journal, 1924, i, 780

Hurst, A. F.: Ibid., 1928, ii, 779.

Luff, A. P.: Ibid., 1929, ii, 1074.

Meulengracht, E.: Lancet, 1935 , ii, 1220.

Nicholas, F. G., and Moncrieff, A.: British Medical Journal, 1927. i. 999.

St. Bartholomew's Hospital Reports, 1934, lxviii, 54.

Sherren, J.: Choyce's System of Surgery, fourth edition.

Smith, D.: British Medical Journal, 1928, ii, 293.

\section{INFLAMMATION: HUNTER'S VIEWS AND MODERN CONCEPTIONS *}

\author{
BY
}

SIR G. LENTHAL CHEATLE, K.C.B., C.V.O., F.R.C.S. CONSULTING SURGEON AND EMERITUS LECTURER IN SURGERY, KING'S COLLEGE HOSPITAL

There is probably no subject of the present day that is so dominated by Hunter as is his work on inflammation. $\mathrm{He}$ came to the conclusion that it was a process of activity, while Lister, working fifty or sixty years later, believed it to be a loss of function and vital activity.

Since these opinions are so directly opposed I thought that it might be interesting to dwell upon notions so divergent, in order to determine which of the two views is better adapted to the requirements of present knowledge. I shall not have time to discuss more than one point upon which Hunter based his view, and then I will take up Lister's work.

\section{Increased Vascularity}

Hunter regarded the increased vascularity he observed in inflammation as being the direct and primary cause of repair. The morphological appearances of a healing ulcer serve to illustrate Hunter's conception. There is a decided increase in the number of blood vessels supplying the base of the ulcer compared with the parts around. Their existence is maintained until the granulation tissue becomes finally covered by epithelium, whereupon they atrophy and disappear, leaving an almost avascular cicatricial tissue. Finally the amount of cicatricial tissue itself diminishes to such an extent as to become almost imperceptible in old wounds that have healed by first intention.

One thing is perfectly obvious here. All the time the tissues are undergoing the growth of repair they are supplied by an increase in the number of blood vessels. Is this increase of blood supply the master of the process as Hunter thought, or is it merely a servant? If it be the uncontrolled master, then why is it that the epithelium and granulation tissue remain on a level? What is there to prevent these tissues from growing to form epithelial and connective tumours?

* Part of the Hunterian Oration delivered before - the Hunterian Society of London, February 24th, 1936.
It is a wonderful and inexplicable fact that when the epithelial cells have completed their function of covering the exposed surface of granulation tissue their superficial spread ceases, and their future. activity is devoted to keeping intact the covering layer they have made. The blood vessels have diminished in number sufficient only for that purpose. Is the definite performance of these epithelial cells the result of the accomplishment of a function? Everything that is happening points to the fact that all the events are under a co-ordinating general control, and that no single one of them can be regarded as a master of the process of healing. In fact it appears that the blood supply and the behaviour of the epithelial and connective tissue elements that compose a healing ulcer are all alike under a predominating control, which regulates the total and combined events, ending in orderly growth.

\section{Healing Processes}

The same considerations arise with even greater potency when the orderly sequence of events occurring in the more complicated and still controlled stages of growth in a healing fracture is observed. The same orderliness can be seen in the new formations that occur in an artery after its ligation. In all these events the processes of new formation are different, and cepend upon the function they are intended to fulfil.

I hope I have given sufficient reason to doubt whether the increase of blood supply is either the sole factor in controlling repair or even its incentive. There can be no doubt that an increased supply of blood cannot alone induce growth. I admit that the existence, growth, and repair of tissues could not be maintained without an adequate blood supply. I know of no instance which can be quoted as an example of growth being stimulated or incited solely by a more than adequate supply of blood.

The healing of varicose ulcers occurs after sympathectomy, when all other attempts have failed. Recently obstinate varicose ulcers have been induced to heal by diathermy in some instances and by short-wave therapy in others. The healing in these instances could be explained by the delivery of an adequate blood supply that was inadequate prior to the sympathectomy. Supposing this explanation to be correct, the subsequent events of the healing process are under an all-powerful control, and they cannot be regulated only by alterations in blood supply. 